\title{
Reference Values for Umbilical Cord Blood Gases of Newborns Delivered in Enshi Tujia and Miao Autonomous Prefecture
}

\author{
Huijie Wu, Qian Yu, Wen Wang, Li Li* \\ Department of Obstetrics, Affiliated Hospital of Hubei University for Nationalities, Enshi, China \\ Email: *376960269@qq.com
}

How to cite this paper: Wu, H.J., Yu, Q., Wang, W. and Li, L. (2018) Reference Values for Umbilical Cord Blood Gases of Newborns Delivered in Enshi Tujia and Miao Autonomous Prefecture. Open Access Library Journal, 5: e5026. https://doi.org/10.4236/oalib.1105026

Received: November 5, 2018

Accepted: November 24, 2018

Published: November 27, 2018

Copyright $\odot 2018$ by authors and Open Access Library Inc.

This work is licensed under the Creative Commons Attribution International License (CC BY 4.0). http://creativecommons.org/licenses/by/4.0/

\section{Open Access}

\begin{abstract}
Objective: To define the normal ranges of umbilical cord blood values in Enshi Tujia and Miao Autonomous Prefecture. Methods: 1266 normal newborns were screened as umbilical cord blood gas samples. Normal neonates are full-term live pregnancies, single births, weight suitable for gestational age and heavier than the gestational age of the newborn without complications. Results: The umbilical cord blood collected from 1266 newborns was analyzed in this study. The calculated reference range of the umbilical arterial $\mathrm{PH}$ was 7.16 - 7.39, of SBE was $-8.25-1.67 \mathrm{mmol} / \mathrm{L}$, of lactic acid was $1.4-7.5$ $\mathrm{mmol} / \mathrm{L}$, and of $\mathrm{HCO}_{3}$ was $15.60-30.70 \mathrm{mEq} / \mathrm{L}$. Conclusions: This study confirmed the normal reference value of umbilical cord blood gas analysis in Enshi Tujia Miao Autonomous Prefecture.
\end{abstract}

\section{Subject Areas}

Gynecology \& Obstetrics

\section{Keywords}

Ethnic Minority, Umbilical Cord Blood, Blood Gas Analysis,

Normal Referencevalue

\section{Introduction}

Umbilical cord blood gas values are commonly indicators to evaluate neonatal birth status at home and abroad. It is an index with high specificity, which can effectively evaluate acid-base status and substance metabolism [1]. The neonatal cord blood gas results were used to evaluate whether the neonates had inhibition or not, to determine the cause of inhibition and to race against time for rescue. 
Umbilical cord blood gas values may also assiste valuations of an infant and indicate the occurrence of an acute, and intrapartum hypoxic event [2]. Similarly, Revathy Natesan S [3] reported the analysis of umbilical cord blood gas in 2212 neonates. The results showed that lactic acid and $\mathrm{pH}$ value were significantly correlated with the adverse outcomes of neonatal hypoxic-ischemic encephalopathy. However, many studies groups have reported that it is particularly susceptible to vary in the parameters of umbilical cord blood gas values, such as fetal age, production mode, maternal acid base balance, fetal hemoglobin concentration and so on. The normal values of the parameters still lack a unified reference range. Kattiya Manomayangkul et al. [4] reported that the so-called "normal" umbilical cord blood gas analysis may also vary depending on race and mode of work.

Enshi Tujia and Miao Autonomous Prefecture are the only minority Autonomous Prefecture in Hubei, China. It has special mountainous terrain, rich Selenium Resources and diet culture. There are a large number of births per year. At the end of 2016, the total population of Enshi was 4,040,100; the annual birth rate was 10.38 per thousand. In 2017, there were 42 thousand and 300 new born population [5]. But there is no statistical report on the normal reference range of umbilical cord blood gas analysis in Enshi. It will be a defect in evaluating the newborn birth situation, and predicting adverse outcomes and prognosis in Enshi Prefecture. This article will make a discussion.

\section{Research Methods}

1) Participants: In 2015-2018 years, a total of full-term pregnancies, single births, suitable gestational age or greater than gestational age in six hospitals in Enshi. The study has been approved by the hospital ethics committee.

2) Excluded objects: 1 minutes or 5 minutes of Apgar score of less than 7, anyone with abnormal symptoms of respiratory symptoms, 1 or more than 1 organ damage, with congenital heart and respiratory disease.

3) Personnel and equipment: The Apgar score was assessed by a trained obstetrician, midwife and newborn pediatrician in delivery room and operation room. Umbilical cord blood analyzer equipment model: Denmark, RADO ABL 90 FLEX.

4) Collection method: The umbilical cord about $10 \mathrm{~cm}$ in length was clamped with two sterile hemostatic forceps near the side of the fetus immediately after delivery without establishing spontaneous breathing. The umbilical cord was cut off at the outside of the clamp. Then the umbilical artery or venous blood was punctured with a heparinized syringe. The blood was sealed and sent to the obstetric Department of obstetrics. The blood gas analysis results obtained from the blood gas analyzer were recorded. The values of $\mathrm{PH}, \mathrm{HCO}_{3}^{-}, \mathrm{cLac}$ and SBE were detected.

5) Statistical methods: SPSS 17.0 software was used for statistical analysis. Apgar scores of $1 \mathrm{~min}$ and $5 \mathrm{~min}(>8)$ were used for single fetus, full-term, suita- 
ble weight and larger than gestational age, which included 1266 cases. The normal range of umbilical artery blood gas parameters is 1.96 standard deviations. Normal distribution method was used for data obeying normal distribution, and percentage method was used for data of skewed distribution to calculate the reference range. $\mathrm{P}<0.05$ was statistically significant.

\section{Results}

One thousand six hundred and one term newborns were assessed in this study. 335 cases were excluded from inclusion criteria after birth. Data from the remaining 1266 newborns were then analyzed. Statistics of inclusion criteria are shown in Figures 1-4. The resulting reference ranges of the arterial umbilical cord blood of the newborns: The PH value was $7.16-7.39$, the SBE value was $-8.25-1.67 \mathrm{mmol} / \mathrm{L}$, the lactic acid value was $1.4-7.5 \mathrm{mmol} / \mathrm{L}$, and the $\mathrm{HCO}_{3}$ value was $15.60-30.70 \mathrm{mEq} / \mathrm{L}$ (Figures $1-4$ ).

\section{Conclusion}

The normal value obtained in the study is slightly lower than the traditional normal range [6]. The analysis may be due to different inclusion criteria or different progress in labor. As long as the blood gas changes are not serious enough to produce organ function or organic damage, they should be considered physiological. Umbilical cord blood gas has been recognized as the most objective and reliable basis for evaluating fetal and neonatal oxygenation and acid-base status. Establishing a normal reference range of umbilical cord blood gas analysis value of neonates in Enshi Prefecture can improve the diagnosis rate of neonatal asphyxia,

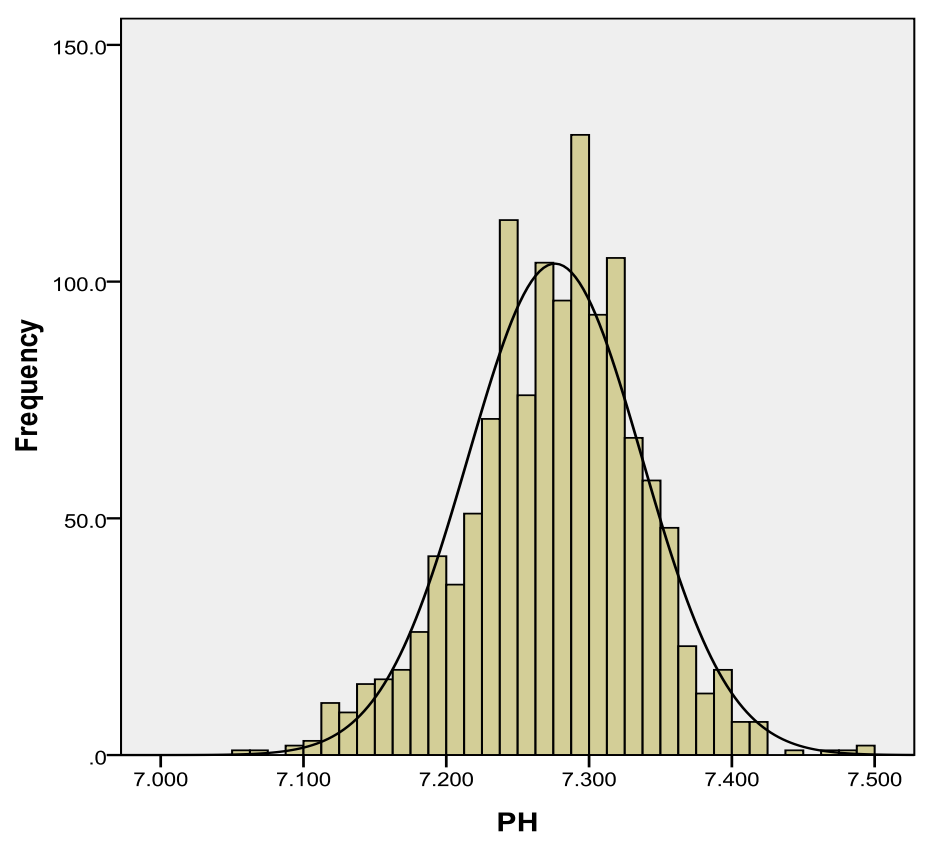
Mean $=7.27612$
Std. Dev. $=.060799$
$N=1,266$

Figure 1. Frequency distribution of umbilical artery $\mathrm{PH}$ value in 1266 vigorous human newborn infantsnormal distribution. 


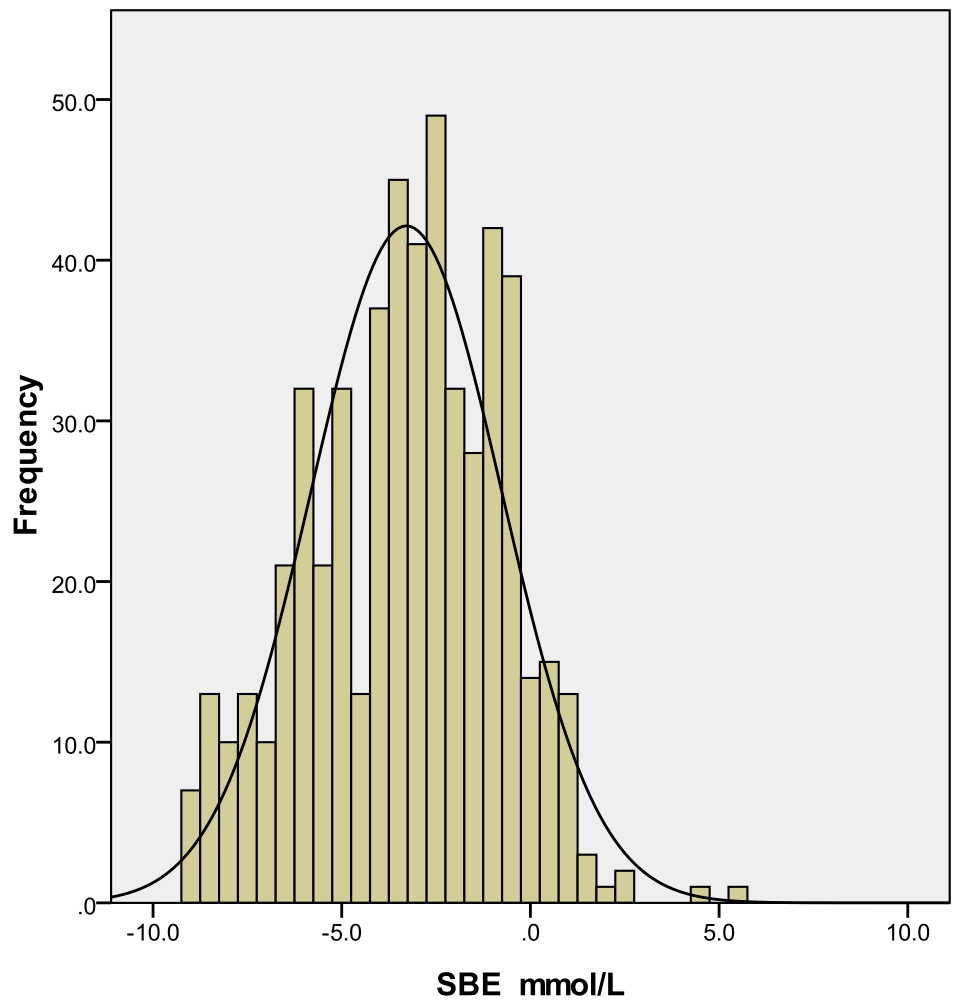

Mean $=-3.287$

Std. Dev. $=2.5302$ $\mathrm{N}=535$

Figure 2. Frequency distribution of umbilical artery SBE value in 535 vigorous human newborn infantsnormal distribution.

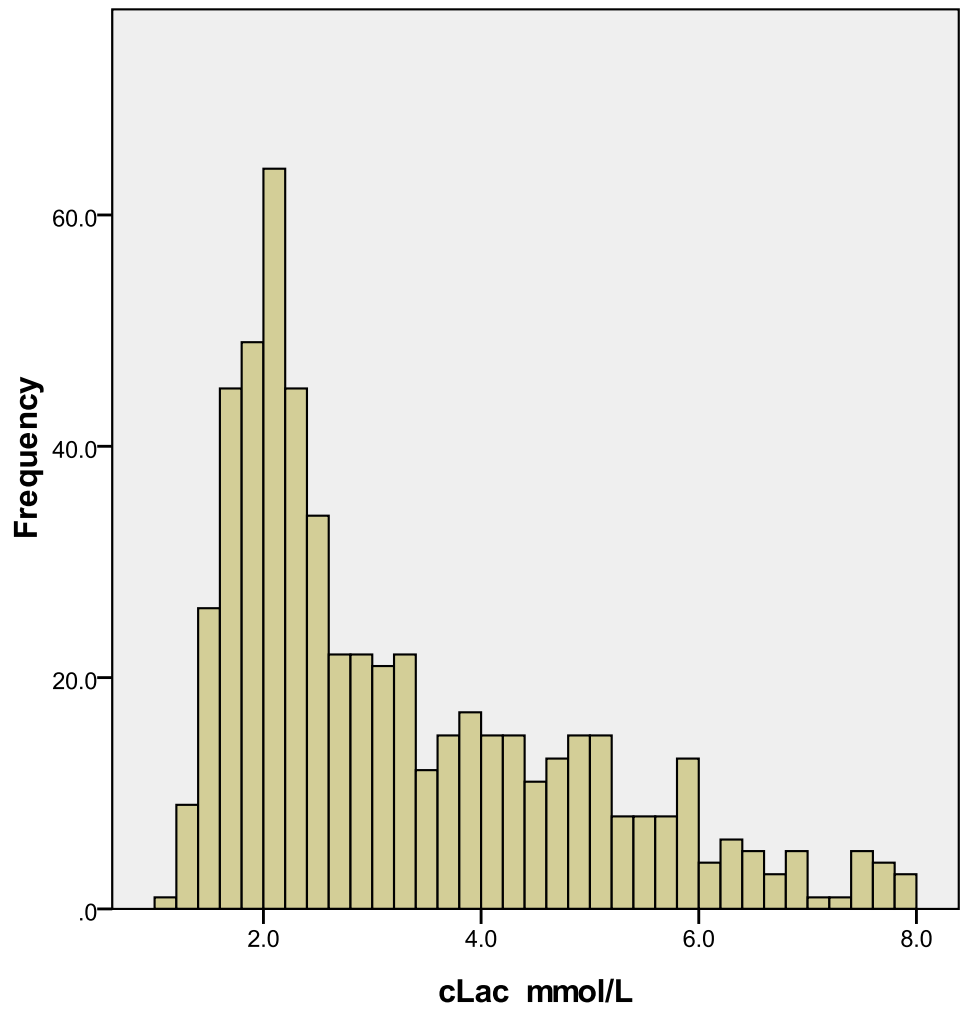

Mean $=3.19$ Std. Dev. $=1.563$ $\mathrm{N}=562$

Figure 3. Frequency distribution of umbilical artery Lac value in 562 vigorous human newborn infantsnormal distribution. 


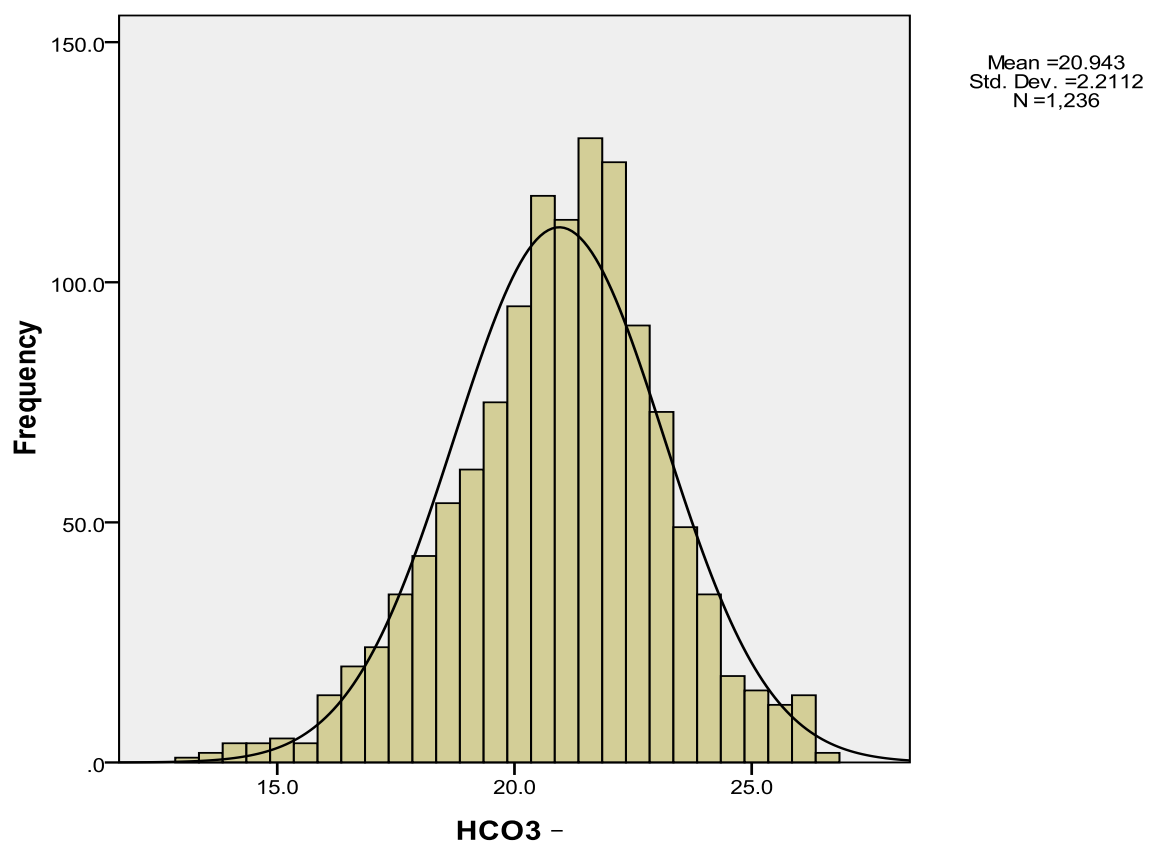

Figure 4. Frequency distribution of umbilical artery $\mathrm{HCO}_{3}^{-}$value in 1236 vigorous human newborn infantsnormal distribution.

reduce the risk rate, improve the specificity of detection, and help to distinguish the causes of neonatal depression. Guiding neonatal further treatment, evaluating neonatal prognosis and even using umbilical cord blood gas analysis results, and avoiding medical disputes have important effects. Therefore, it is important to establish a normal reference range for umbilical cord blood gas analysis to improve the diagnosis of neonatal asphyxia, guide further rescue, and reduce the risk of adverse outcomes of neonates.

\section{Conflicts of Interest}

The authors declare no conflicts of interest regarding the publication of this paper.

\section{References}

[1] Neonatal Umbilical Artery Blood Gas Index Research Group (2010) Multi Center Clinical Study of Umbilical Artery Blood Gas Index in Diagnosis of Neonatal Asphyxia. Chinese Journal of Pediatrics, 48, 668-673.

[2] Manomayangkul, K., Arunota, S., et al. (2016) Reference Values for Umbilical Cord Blood Gases of Newborns Delivered by Elective Cesarean Section. Journal of the Medical Association of Thailand, 99, 611-617.

[3] Revathy Natesan, S. (2016) Routine Measurements of Cord Arterial Blood Lactate Levels in Infants Delivering at Term and Prediction of Neonatal Outcome. The Medical Journal of Malaysia, 71, 131-133.

[4] Manomayangkul, K., Siriussawakul, A., Nimmannit, A., et al. (2016) Reference Values for Umbilical Cord Blood Gases of Newborns Delivered by Elective Cesarean Section. Journal of the Medical Association of Thailand, 99, 611-617. 
[5] The People's Government of Enshi Tujia and Miao Autonomous Prefecture, May 5, 2017. Enshi National Economic and Social Development Bulletin. http://www.enshi.gov.cn/zzf/zc/

[6] Arikan, G.M., Scholz, H.S., Petru, E., et al. (2000) Cord Blood Oxygen Saturation in Vigorous Infantsat Birth: What Is Normal? BJOG, 107, 987-994.

https://doi.org/10.1111/j.1471-0528.2000.tb10401.x 